\title{
Chlorosulfolipid (Danicalipin A) Membrane Structure: Hybrid Molecular Dynamics Simulation Studies
}

\author{
Junyeol Lee, Seungmin Yoon, and Rakwoo Chang* \\ Department of Applied Chemistry, University of Seoul, Seoul 02504, Republic of Korea \\ E-mail: rchang90@uos.ac.kr \\ Phone: +82-2-6490-2464. Fax: +82-2-6490-2463
}




\section{Angle distribution of Danicalipin A}

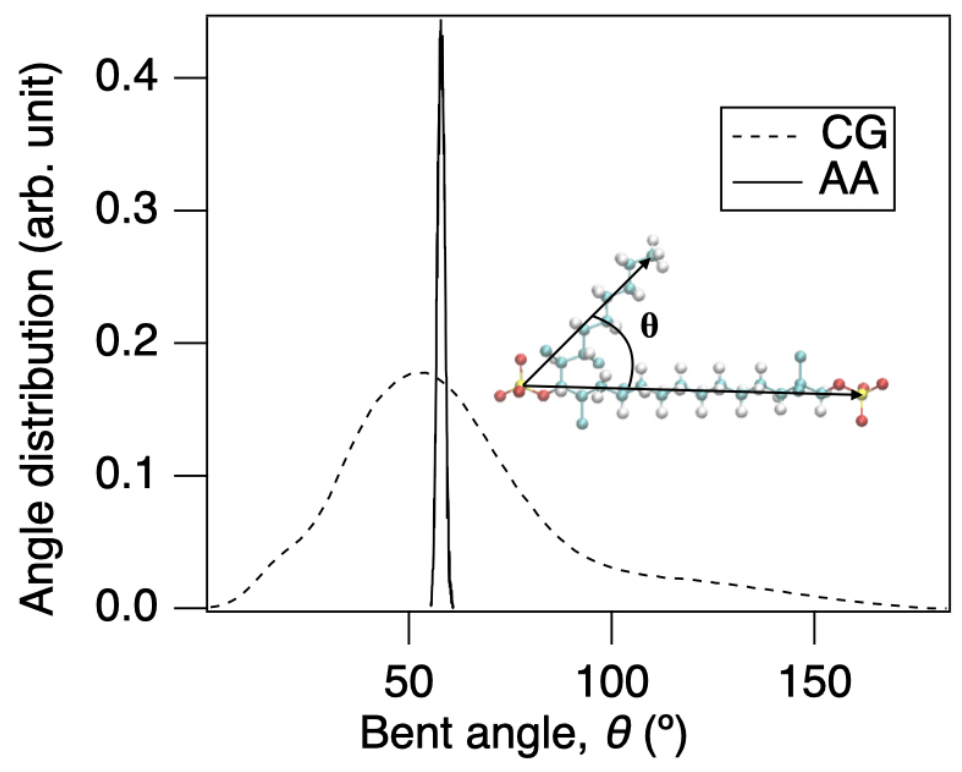

Figure S1: Bent angle distribution of Danicalipin A lipid in both coarse-grained (CG) and atomistic (AA) membrane systems. The bent angle in the CG model is defined as Qa (head) - Qa (tail) - C1. The mean bent angle, $\langle\theta\rangle$, is $66 \pm 3^{\circ}$ for $\mathrm{CG}$ and $60.0 \pm 0.5^{\circ}$ for AA. 


\section{Stability test of various membrane structures comprising}

\section{Danicalipin A}

(a)

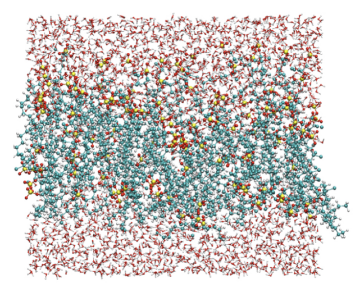

(c)

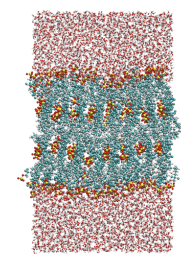

(e)

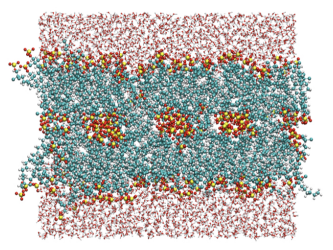

(b)

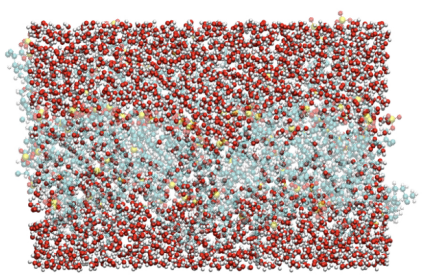

(d)

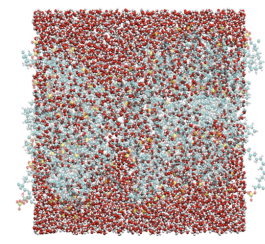

(f)

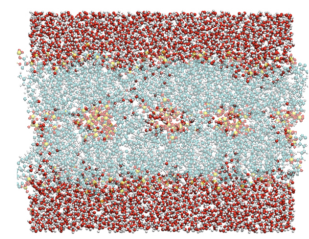

Figure S2: Initial and final configurations of various membrane structures of Danicalipin A: (a), (b) - LMM (monolayer with linear geometry), (c), (d) - LBM (bilayer with linear geometry), and (e), (f) - BBM (bilayer with bent geometry). 